\title{
TU/e EmonOWEN

\section{An integrated 13.56-MHz RFID tag in a printed organic complementary TFT technology on flexible substrate}

\section{Citation for published version (APA):}

Fiore, V., Battiato, P., Abdinia, S., Jacobs, S., Chartier, I., Coppard, R., Klink, G., Cantatore, E., Ragonese, E., \& Palmisano, G. (2015). An integrated 13.56-MHz RFID tag in a printed organic complementary TFT technology on flexible substrate. IEEE Transactions on Circuits and Systems I: Regular Papers, 62(6), 1668-1677. [7108060]. https://doi.org/10.1109/TCSI.2015.2415175

DOI:

10.1109/TCSI.2015.2415175

Document status and date:

Published: 01/06/2015

\section{Document Version:}

Accepted manuscript including changes made at the peer-review stage

\section{Please check the document version of this publication:}

- A submitted manuscript is the version of the article upon submission and before peer-review. There can be important differences between the submitted version and the official published version of record. People interested in the research are advised to contact the author for the final version of the publication, or visit the $\mathrm{DOI}$ to the publisher's website.

- The final author version and the galley proof are versions of the publication after peer review.

- The final published version features the final layout of the paper including the volume, issue and page numbers.

Link to publication

\section{General rights}

Copyright and moral rights for the publications made accessible in the public portal are retained by the authors and/or other copyright owners and it is a condition of accessing publications that users recognise and abide by the legal requirements associated with these rights.

- Users may download and print one copy of any publication from the public portal for the purpose of private study or research.

- You may not further distribute the material or use it for any profit-making activity or commercial gain

- You may freely distribute the URL identifying the publication in the public portal.

If the publication is distributed under the terms of Article 25fa of the Dutch Copyright Act, indicated by the "Taverne" license above, please follow below link for the End User Agreement:

www.tue.nl/taverne

Take down policy

If you believe that this document breaches copyright please contact us at:

openaccess@tue.nl

providing details and we will investigate your claim. 


\title{
An Integrated 13.56-MHz RFID Tag in a Printed Organic Complementary TFT Technology on Flexible Substrate
}

\author{
Vincenzo Fiore, Student Member, IEEE, Placido Battiato, Sahel Abdinia, Stephanie Jacobs, \\ Isabelle Chartier, Romain Coppard, Gerhard Klink, Eugenio Cantatore, Senior Member, IEEE, \\ Egidio Ragonese, Senior Member, IEEE, and Giuseppe Palmisano, Senior Member
}

\begin{abstract}
This paper presents the first printed organic 13-MHz RFID on flexible substrate. The proposed solution includes a planar near field antenna bonded to an RFID tag, which is printed on flexible foil using an organic complementary TFT technology. Thanks to an active envelope detector, ASK modulation with modulation depth as low as $20 \%$ can be adopted to increase the available input power for the rectifier. The RFID functionality is demonstrated at the internally generated supply voltage of $24 \mathrm{~V}$, for a reading range of $2-5 \mathrm{~cm}$ and a bit-rate up to $50 \mathrm{bit} / \mathrm{s}$. With more than 250 transistors on the same foil, this work represents the most complex circuit ever published in a printed organic complementary TFT technology.
\end{abstract}

Index Terms - ASK modulation, active detection, mixed analog-digital circuits modulation index, organic circuits, pentacene, polyimide, radio frequency identification, sub-threshold, silent tag, spiral antenna, thin film transistor.

\section{INTRODUCTION}

$\mathrm{P}_{\mathrm{cos}}$ rinted organic electronics has gained increasing consideration as a cost-effective alternative to silicon, especially in those applications where cheap or disposable devices are required [1]-[5]. In the roadmap of printed electronics, radio frequency identification (RFID) has an important place due to the huge available market still covered by bar codes. Despite this great interest, state-of-the-art printed organic technologies do not enable the implementation of a complete RFID tag yet. This is mainly due to the complexity of a tag, which includes a near-field antenna, radio frequency (i.e., 13-MHz) detection, mixed analog/digital

Manuscript received Dic. 05, 2014, revised Feb. 20, 2015, accepted Feb. 26, 2015. This work was funded in the framework of the EU FP7 Project COSMIC (grant agreement n. 247681).

V. Fiore, P. Battiato, and G. Palmisano are with DIEEI, Università di Catania, Catania, I-95125, Italy. (e-mail: vincenzo.fiore@dieei.unict.it, battiatoplacido@gmail.com, giuseppe.palmisano@dieei.unict.it).

S. Abdinia and E. Cantatore are with Eindhoven University of Technology, 5600MB Eindhoven, The Netherlands (e-mail: S.Abdinia@tue.nl, E.Cantatore@tue.nl).

S. Jacobs, S. Chartier and R. Coppard are with CEA-LITEN, Grenoble, F-38054, France (email: stephanie.jacob@cea.fr, isabelle.chartier@cea.fr, romain.coppard@cea.fr).

G. Klink is with Fraunhofer EMTF, 80686 Munich, Deutschland (email: Gerhard.Klink@emft.fraunhofer.de)

E. Ragonese is with STMicroelectronics, Catania, I-95121, Italy (e-mail: egidio.ragonese@ st.com).

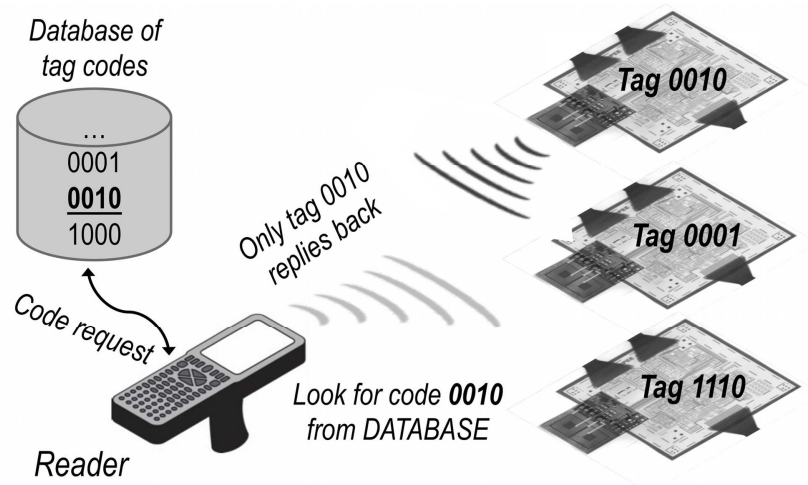

Fig. 1. "Silent tag" identification scheme used by the proposed organic RFID.

functionalities and harvesting capability (for passive RFID). Moreover, RFID security typically requires a level of circuit complexity that cannot be achieved nowadays by organic electronics. Recently, several promising results based on lithographic organic processes have been published. Specifically, an inductive-coupled organic RFID operating at 13.56 MHz has been demonstrated using a p-type organic technology on foil [6]. A complementary organic technology has been used for the $13.56-\mathrm{MHz}$ transponder in [7]. A complementary hybrid organic/metal-oxide process has been exploited to demonstrate bidirectional communication in an HF RFID [8], [9]. This last solution adopts passive diode-based envelope detection together with OOK modulation, resulting in limited sensitivity and reduced reading range.

In recent years, a printed complementary organic TFT (C-OTFT) technology has been developed [10], [11] and successfully employed to design digital and analog circuits [12], [13], a 4-bit analog-to-digital converter [14] and a light sensor [4]. This technology has been recently used to explore the feasibility of a RFID tag with active envelope detection, making possible to demodulate ASK PWM-coded signals with modulation depth $(h)$ as low as $25 \%$ [15]. Starting from this result, a fully integrated solution for a printed $13.56-\mathrm{MHz}$ RFID tag on flexible substrate has been designed. The RFID has been manufactured using an improved version of the C-OTFT process used in [15] and includes a 13-MHz planar antenna bonded to the printed organic tag. The tag integrates a rectifier for power supply, a receiver with an active envelope detector, and a digital section for code recognition and reply.

The proposed RFID exploits an identification scheme called "silent tag" [16]. Each silent tag is customized with its own 
code and answers only to readers sending this code, thus avoiding the need of anti-collision or disabling mechanisms. The main advantage is that a tag search is possible only if a list of the tags that can be offered to the reader (e.g., the tags in the shop) is known in advance (see Fig. 1). In this way, tag security is ensured with no need for encryption, which makes this solution especially suitable for organic printed electronics.

The paper is organized as follows. Section II describes the RFID architecture, fabrication technologies and circuit design. Measurements of both building blocks and overall tag are discussed in Section III. Conclusions are drawn in Section IV.

\section{SYSTEM DESCRIPTION: TECHNOLOGY AND DESIGN}

The architecture of the proposed RFID tag is shown in Fig. 2. The tag includes a receiver, consisting of an active envelope detector (ED) and clock/data recovery circuitry, a rectifier, and a code recognition unit. Both ED and the rectifier are inductively coupled to the reader by means of a two-coil antenna on a polyimide foil. A PWM coding is adopted with bit " 1 " and " 0 " corresponding to a duty cycle of $70 \%$ and $30 \%$ high, respectively. A bit rate of $50 \mathrm{bit} / \mathrm{s}$ has been chosen. The rectifier provides the internal supply voltage, $V_{\mathrm{DD}}$, to the other blocks. The ED extracts the ASK envelope from the $13.56-\mathrm{MHz}$ carrier and drives the recovery circuitry. The clock decoder detects the rising edge of the envelope signal, ENV, thus providing a synchronizing clock, CLOCK, to the code recognition unit. Signal CLOCK is properly delayed and then used by the D-flip-flop (D-FF) to extract the received data stream, DATA, by sampling signal ENV. The code recognition unit is designed to receive a sequence of "reset" and "identity" codes and consists of two modules. The reset module (RM) synchronizes all the tags in the reader range with the start of the following identity transmission code. The identity verification module (IVM) compares the received code with the tag identity and in case of code matching enables the response back to the reader by using the modulator (not included in the block diagram for the sake of simplicity). It is driven by a ring oscillator, which is activated by signal MOD.

\section{A. Complementary Organic TFT Technology}

The adopted printed complementary organic technology is manufactured on an $11 \times 11 \mathrm{~cm}^{2}$ flexible foil by CEA-Liten [10], [11]. The TFTs are implemented in a top-gate bottom-contact multi-finger structure with a $20-\mu \mathrm{m}$ channel length on $125-\mu \mathrm{m}$ thick polyethylene-naphtalate (PEN) substrate. A simplified cross-section of both p-type and n-type TFTs is shown in Fig. 3. A microphotograph of a multifinger OTFT ( $W=2000 \mu \mathrm{m}, L=20 \mu \mathrm{m})$ is shown in Fig. 4. Since the present printing resolution of metallic inks can barely reach line/spacing resolution of $20 \mu \mathrm{m}$ as well as the required flatness, a direct patterning approach by means of laser ablation was chosen to pattern the source/drain electrodes. Fig. 5 summarizes main process steps of the adopted printed C-OTFT technology. Gold is sputtered to a thickness of $30 \mathrm{~nm}$ on the PEN and then patterned using laser beam to form the
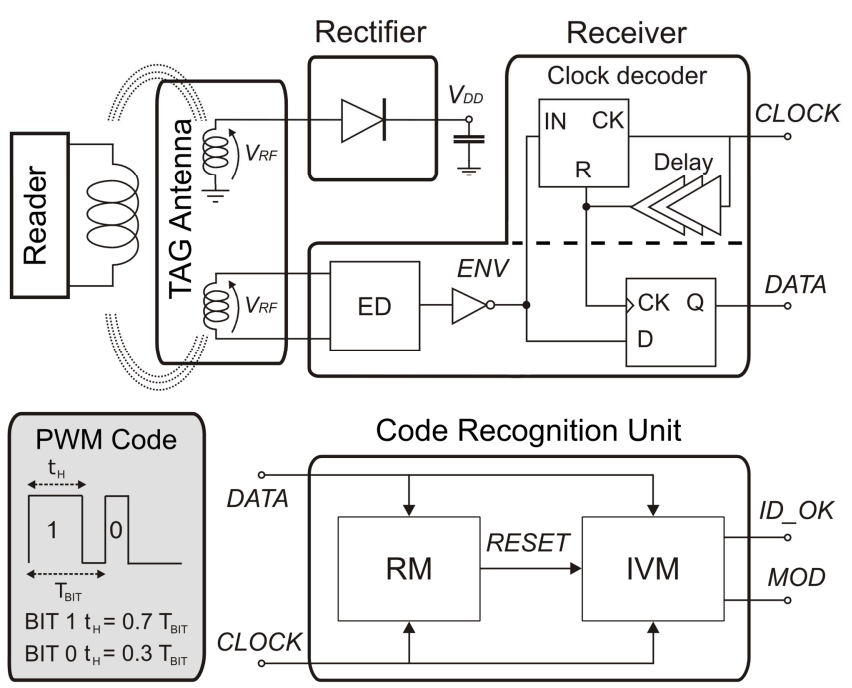

Fig. 2. Block diagram of the 13.56-MHz RFID tag and PWM coding scheme.

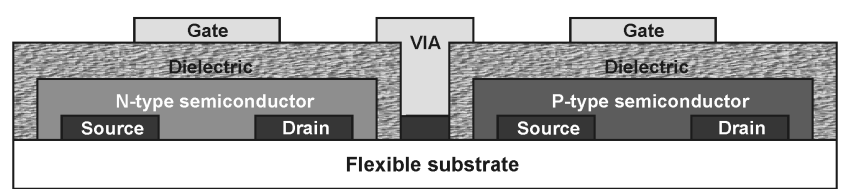

Fig. 3. C-OTFT cross-section of the adopted technology.

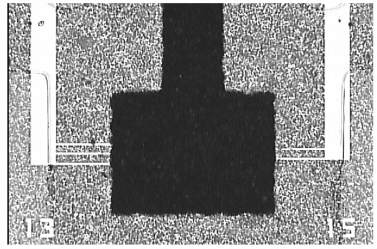

(a)

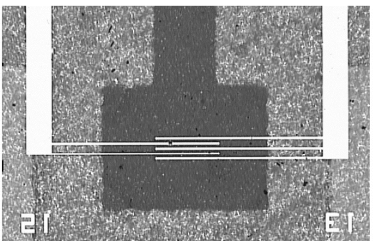

(b)
Fig. 4. Multifinger OTFT photo. (a) Top view. (b) Bottom view $(W=2000 \mu \mathrm{m}, L=20 \mu \mathrm{m})$.

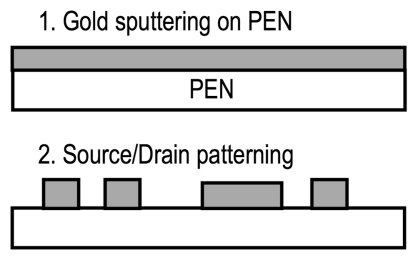

8. Insulator printing leaving open areas for via holes

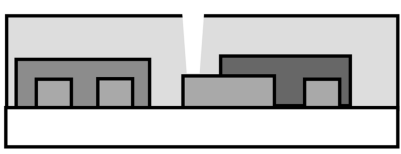

9. Adhesion promoter deposition

3. SAM Deposition

4. n-type organic semiconductor printing
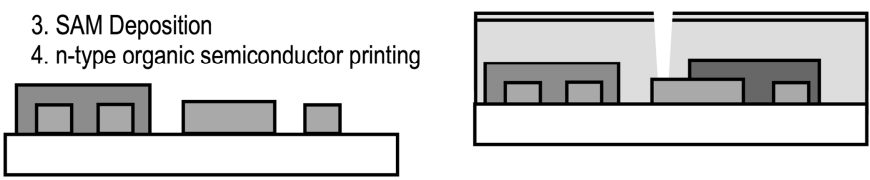

10. Gate printing (forming also the

5. $O_{2}$ plasma

6. SAM Deposition

7. p-type organic semiconductor printing
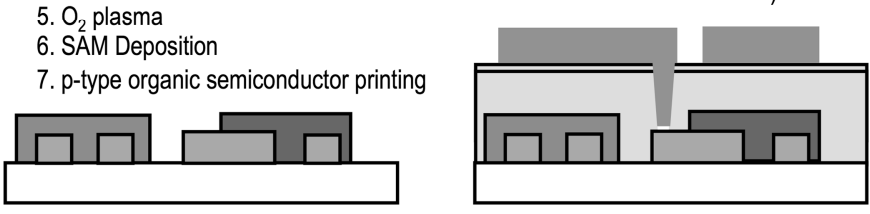

Fig. 5. Simplified process flow of the adopted C-OTFT technology. 
source and drain electrodes as well as the first level of interconnections. Then, the n-type organic semiconductor (Polyera ActivInk ${ }^{\circledR}$ ) is patterned by printing methods. The source/drain electrodes and the PEN are cleaned with an $\mathrm{O}_{2}$ plasma to prepare the surface for the self-assembled monolayer (SAM) deposition and p-type organic semiconductor (Merck Lisicon S1200) printing. The common fluoropolymer dielectric (Merck Lisicon D139, $750 \mathrm{~nm}$ thickness) is then screen-printed on top of both semiconductors and then annealed, leaving open areas for via holes. Finally, a silver-ink conductor is screen-printed, forming OTFT gate electrodes and the second level of interconnections. Reliability and performance of TFTs were improved for this work by re-engineering the gate stack, using an adhesion promoter. Firstly, the gate leakage current was reduced, thus improving hard yield and also dielectric robustness during circuits test. Secondly, the gate capacitance was increased. Actually, in a former gate stack the silver-ink was formulated with adhesive to guarantee adhesion on the fluoropolymer dielectric. However, it was found that this approach added a parasitic capacitance in series with the dielectric one [17]. This drawback was overcome with a silver ink that no longer needs adhesive and results in a higher gate capacitance. Measurements performed on a $1-\mathrm{mm}^{2}$ Metal/Insulator/Metal (MIM) capacitor showed a $23 \%$ increase of the capacitance (i.e., $2.15 \mathrm{nF} / \mathrm{cm}^{2}$ ), which in turn leads to an increase of the OTFT mobility $\left(\mu_{\mathrm{SAT}}\right)$ typically by around $80 \%$ and $27 \%$ for the p-type and n-type transistors, respectively. The process also provides optional carbon-ink resistors that are screen-printed after organic semiconductors patterning and before the final screen-printing of the gate layer. Main electrical parameters of both p-type and n-type TFTs are summarized in Table I for channel length of $100 \mu \mathrm{m}$ and $20 \mu \mathrm{m}$. It is worth noting that the adoption of the new silver ink allows an outstanding $\mu_{\mathrm{SAT}}$ of $2.7 \mathrm{~cm}^{2} / \mathrm{V} \cdot \mathrm{s}$ to be achieved for $100-\mu \mathrm{m}$ p-type TFTs. The better performance can be easily highlighted by comparing the output characteristics of both p-type and n-type transistors with standard and new silver ink, as shown in Fig. 6. The OTFT current capability is more than doubled for both 2000/20 p-type and n-type transistors for a gate voltage of $40 \mathrm{~V}$, that is the maximum supply voltage adopted in previous work [15]. Most importantly, the curves at $20-\mathrm{V}$ gate voltage show that both devices can operate in sub-threshold region. Moreover, transistor output impedance is high even for drain voltages as low as $10 \mathrm{~V}$. This feature was extensively used in this work to enable both analog and digital circuit operation at reduced supply voltage.

\section{B. Antenna Fabrication Technology and Design}

The 13.56-MHz antenna was fabricated with a semi-additive electroplating process in a roll-to-roll manufacturing mode. A substrate polyimide foil was chosen as highly temperature stable substrate to enable assembly of surface mount devices (SMDs) by soldering. As shown in Fig. 7, the process starts with metallizing the $50-\mu \mathrm{m}$ thick polyimide film with 500-nm copper in a roll-to-roll sputter
TABLE I. COMPARISON OF MAIN ELECTRICAL PARAMETERS OF C-OTFTS DEPENDING ON THE GATE SILVER-INK

\begin{tabular}{|c|c|c|c|c|}
\hline \multirow[b]{2}{*}{ Parameters } & \multicolumn{2}{|c|}{ p-type TFT } & \multicolumn{2}{|c|}{ n-type TFT } \\
\hline & $\begin{array}{l}\text { Standard } \\
\text { silver ink }\end{array}$ & $\begin{array}{c}\text { New } \\
\text { silver ink }\end{array}$ & $\begin{array}{l}\text { Standard } \\
\text { silver ink }\end{array}$ & $\begin{array}{c}\text { New } \\
\text { silver ink }\end{array}$ \\
\hline \multicolumn{5}{|c|}{$L=100 \mu \mathrm{m}$} \\
\hline Carrier mobility $\left[\mathrm{cm}^{2} / \mathrm{V} \cdot \mathrm{s}\right]$ & 1.5 & 2.7 & 0.55 & 0.7 \\
\hline Threshold voltage [V] & -20 & -22 & 18 & 17 \\
\hline ION/lofF & $\sim 10^{7}$ & $>2 \cdot 10^{7}$ & $>2 \cdot 10^{7}$ & $>10^{7}$ \\
\hline \multicolumn{5}{|c|}{$\mathrm{L}=20 \mu \mathrm{m}$} \\
\hline Carrier mobility $\left[\mathrm{cm}^{2} / \mathrm{V} \cdot \mathrm{s}\right]$ & 0.8 & 1.5 & 0.19 & 0.24 \\
\hline Threshold voltage [V] & -24 & -25 & 15 & 14 \\
\hline $\mathrm{I}_{\mathrm{ON}} / \mathrm{l}_{\mathrm{OFF}}$ & $>2 \cdot 10^{7}$ & $>5 \cdot 10^{7}$ & $\sim 10^{7}$ & $>10^{7}$ \\
\hline
\end{tabular}
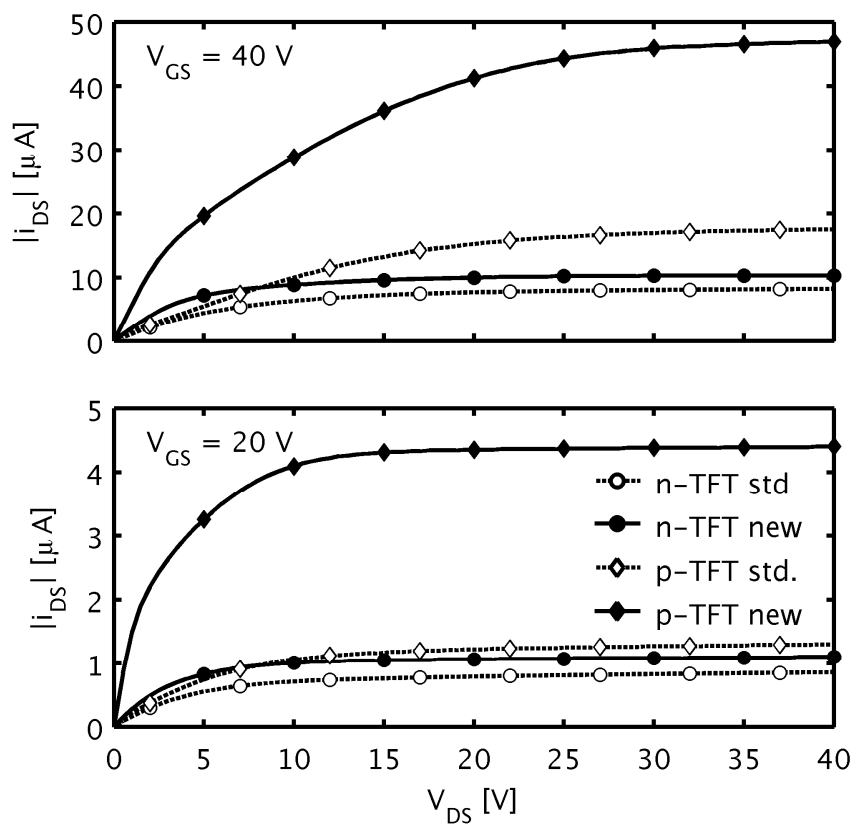

Fig. 6. Output characteristics of OTFTs with standard and new silver ink $(W=2000 \mu \mathrm{m}, L=20 \mu \mathrm{m})$ for $V_{\mathrm{GS}}=40 \mathrm{~V}$ and $V_{\mathrm{GS}}=20 \mathrm{~V}$.

machine. To get good adhesion between substrate and metallization a very thin tie layer of chromium $(\sim 7 \mathrm{~nm})$ is applied. Afterwards, a photolithography step is performed, starting with laminating a $18-\mu \mathrm{m}$ thick dry resist on the substrate foil and its exposure to a broadband UV source through a 9" mask with an exposure field of 200 by $200 \mathrm{~mm}^{2}$. Development is done with an alkaline soda solution in a pass-through spray developer line. Subsequently, the copper conductor lines are electroplated in the resist openings to a height of $9 \mu \mathrm{m}$. The resist is removed and finally the sputtered copper layer and the chromium tie layer are etched away. Due to the copper etching process, the conductor thickness is slightly decreased, ending up in a total thickness of $8 \mu \mathrm{m}$, which corresponds to a sheet resistance of $2.5 \mathrm{~m} \Omega / \mathrm{sq}$. For closing the antenna coil a conductor bridge was fabricated by screen printing. The coil windings are first insulated by printing and curing a dielectric paste (ESL1901-D). Then, the 


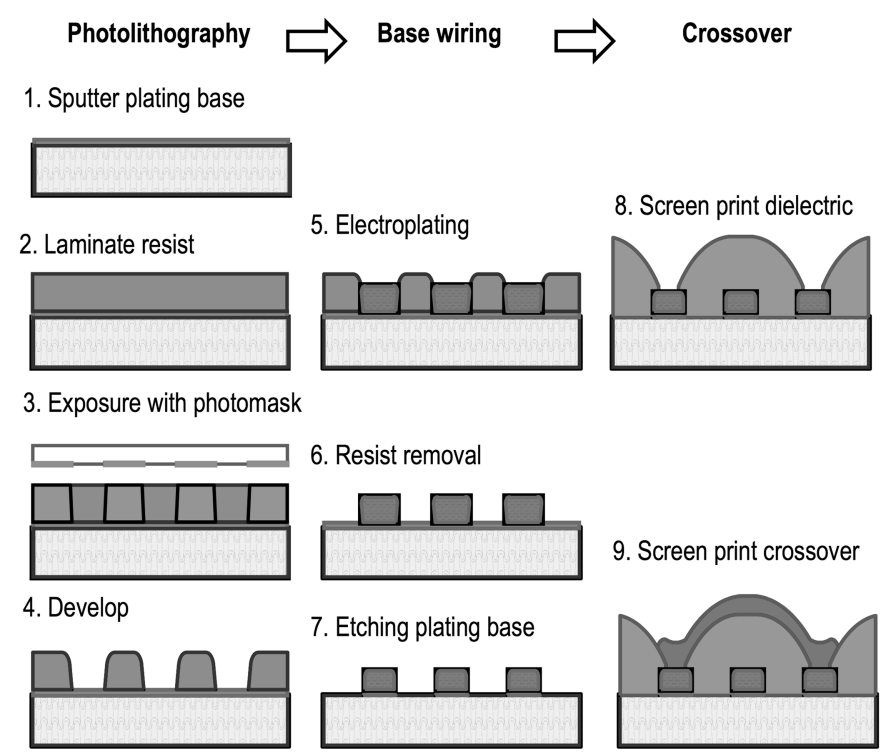

Fig. 7. Antenna fabrication process flow.

bridge is printed with silver paste (ESL1901-S). Curing is done in a belt oven with a peak temperature of $90{ }^{\circ} \mathrm{C}$. The conductive bridge has a sheet resistance of $21 \mathrm{~m} \Omega / \mathrm{sq}$. A value of $8.1 \mathrm{pF} / \mathrm{mm}^{2}$ was measured for the parasitic capacitance between silver bridge and copper coil. A photograph of the fabricated antenna on foil is shown in Fig. 8, whereas its main parameters are detailed in Table II. As highlighted in the photo, the antenna actually consists of two windings. The outer single-ended coil and the inner differential coils with center tap are used by the rectifier and the receiver, respectively, for the coupling with the reader antenna. Two capacitors $\left(C_{\mathrm{RECT}}\right.$ and $\left.C_{\mathrm{RX}}\right)$ are adopted to tune the antenna resonance at $13.56 \mathrm{MHz}$. This two-coil antenna structure highly complies with the proposed RFID architecture (see Fig. 2), which exploits a single-ended rectifier and a differential-like ED to maximize ac-dc conversion efficiency and compensate for the high TFT parasitic capacitances, respectively. The use of two antennas also gives a degree of freedom in the design of the coil inductances, which can be independently optimized. Since the estimated input capacitance of the rectifier was $70 \mathrm{pF}$, the single-ended coil inductance and the external capacitance, $C_{\mathrm{RECT}}$, were set to about $725 \mathrm{nH}$ and $120 \mathrm{pF}$, respectively, thus maintaining adequate tuning against process tolerances. Given the inductance specification of the outer coil, its geometrical parameters were set by using simple equations for planar inductors [18], [19] (constrained to an area of about $5 \times 2.5 \mathrm{~cm}^{2}$ ). Thanks to the lower input capacitance of the envelope detector with respect to the rectifier one, the differential coil was designed to maximize the inductance value by filling the available internal space, thus achieving a high $Q L$ product. Finally, to better estimate the overall antenna performance, which is also affected by a magnetic coupling between the two coils, 2-D electromagnetic simulations were carried out in Momentum MW. Based on these simulations, a value of capacitor $C_{\mathrm{RX}}$ of about $60 \mathrm{pF}$ was required to tune the receiver antenna at $13.56-\mathrm{MHz}$ for a distance of $5 \mathrm{~cm}$ from the

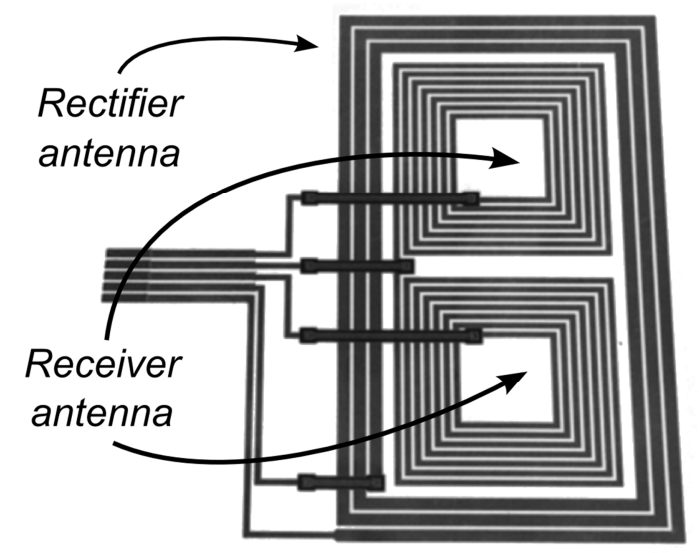

Fig. 8. Photograph of the fabricated $13-\mathrm{MHz}$ antenna on polyimide foil.

TABLE II. 13-MHz ANTENNA DESIGN PARAMETERS

\begin{tabular}{lcc}
\hline \hline Parameters & $\begin{array}{c}\text { Rectifier } \\
\text { single-ended coil }\end{array}$ & $\begin{array}{c}\text { Receiver } \\
\text { differential coil }\end{array}$ \\
\hline Number of turns & 3 & $7(\times 2)$ \\
Width [mm] & 1 & 0.5 \\
Spacing [mm] & 0.3 & 0.3 \\
Inner diameters [mm] & $40 / 20$ & 7.4 \\
Inductance [nH] & 725 & $838(\times 2)$ \\
\hline
\end{tabular}

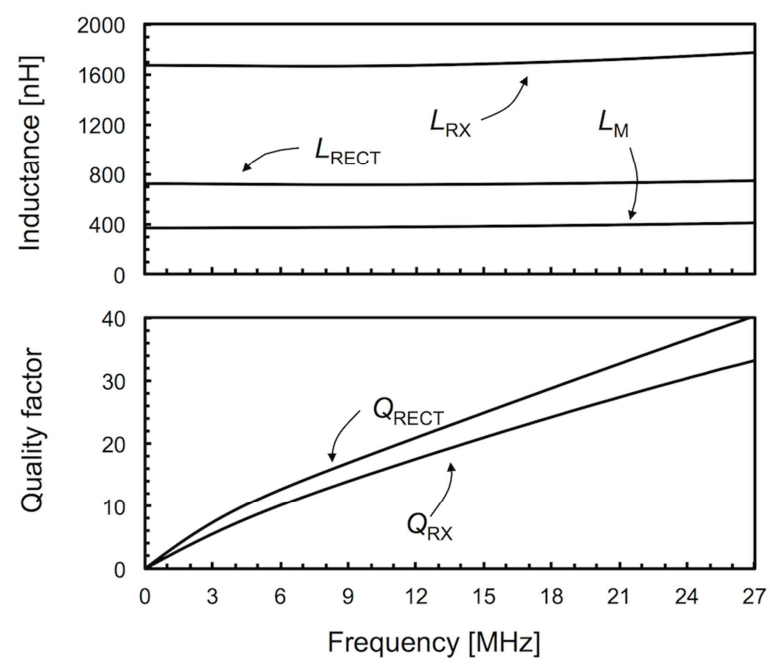

Fig. 9. Antenna electrical performance.

reader antenna and a 190-pF capacitance on the rectifier coil. The simulation results were further confirmed by $S$-parameter measurements of the fabricated samples, shown in Fig. 9. On the basis of the displayed antenna performance, for an equivalent load of $11 \mathrm{k} \Omega / / 190 \mathrm{pF}$ at the rectifier coil, the estimated $13-\mathrm{MHz}$ voltage induced on both antenna coils is about $60 \mathrm{~V}_{\mathrm{PP}}$, provided that the maximum allowable magnetic field of $7.5 \mathrm{~A} / \mathrm{m}$ is used according to ISO-IEC 14443-2. Moreover, system simulations confirmed that the induced voltage on antenna coils remains quite constant when reducing the reading distance. Indeed, the coupling coefficient increases at lower distances, but at the same time it worsens the impedance matching. 


\section{Rectifier and Modulator}

The rectifier is often the bottleneck of passive RFIDs, especially in printed OTFT technologies whose transistor performance is affected by a high threshold voltage $\left(V_{\mathrm{T}}\right)$, typically in the order of several volts. Moreover, low carrier mobility and high parasitic capacitances further limit the frequency performance and hence the rectifier sensitivity. An experimental analysis on the rectifying potentiality of our technology in its first generation is carried out in [20] by testing diode-connected structures. This study pointed out the validity of threshold voltage cancellation techniques to improve the rectifier performance, even at high frequencies, when the mobility degradation plays a significant role in OTFTs. The schematic of the rectifier included in the RFID tag is shown in Fig. 10. It employs a 4-stage topology based on the Dickson charge pump [21], [22]. Differently from the previously adopted topology [15] that is a second-order solution [23], first-order threshold voltage compensation was preferred. The circuit uses mainly p-type transistors that perform better than n-type ones with only an n-type TFT first stage to make possible threshold-voltage compensation. Actually, the gate of the p-type (n-type) transistors is not shorted to the drain, but is connected to another node on the chain, which provides a lower (higher) dc voltage with the same ac phase of the drain signal. Specifically, the gates of M1 and M4 are connected to $V_{2}$ and the gates of M2 and M3 to ground and $V_{1}$, respectively, according to the first-order threshold compensation scheme. This compensation technique, together with the multiple-stage approach, allows a reasonable $V_{\text {OUT }}$ (i.e., $V_{\mathrm{DD}}$ ) to be achieved, even at input voltages that are rather small compared with the TFT threshold voltages.

The modulator is implemented with an n-type transistor, which is connected to the rectifier input. The modulator changes the overall load of the rectifier coil according to the bit to be transmitted, thus performing backscattering.

\section{D.Receiver}

The key block of the receiver is the envelope detector (ED). Indeed, its performance determines the sensitivity of the overall receiver and the capability of demodulating ASK PWM-coded signals with low $h$, which is important to preserve high average power at the rectifier input. A simplified schematic of ED is shown in Fig. 11 along with a qualitative sketch of the main waveforms. The core of ED includes the p-type pair, M1-M2, the self-biased load performed by $\mathrm{M} 3$ and the low-pass filter $R_{\mathrm{L}} C_{\mathrm{L}}$, and the comparator, M4-M7. The input pair driven by the $13.56-\mathrm{MHz}$ RF signal produces a pulsed current, $i_{\mathrm{O}}$, whose slowly variable component within the RF period is related to the input envelope signal. Specifically, current $i_{\mathrm{O}}$ is composed of a high-frequency component, $i_{\mathrm{RF}}$, (i.e., mainly even harmonics of the RF signal), an average component, $I_{\mathrm{AV}}$, and the envelope signal, $i_{\mathrm{ENV}}$. Component $i_{\mathrm{RF}}$ flows into the high parasitic capacitance, $C_{\mathrm{P}}$, at the drain node of M1-M2, hence it is filtered out in a large amount. Current $I_{\mathrm{AV}}$ flows into M3 and produces the average output voltage, $V_{\mathrm{AV}}$, thanks to the

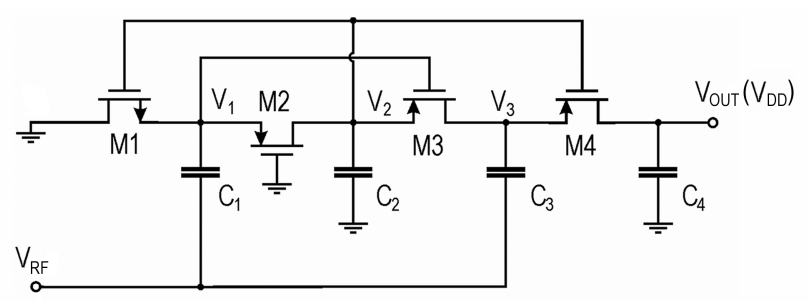

Fig. 10. Schematic of the rectifier.

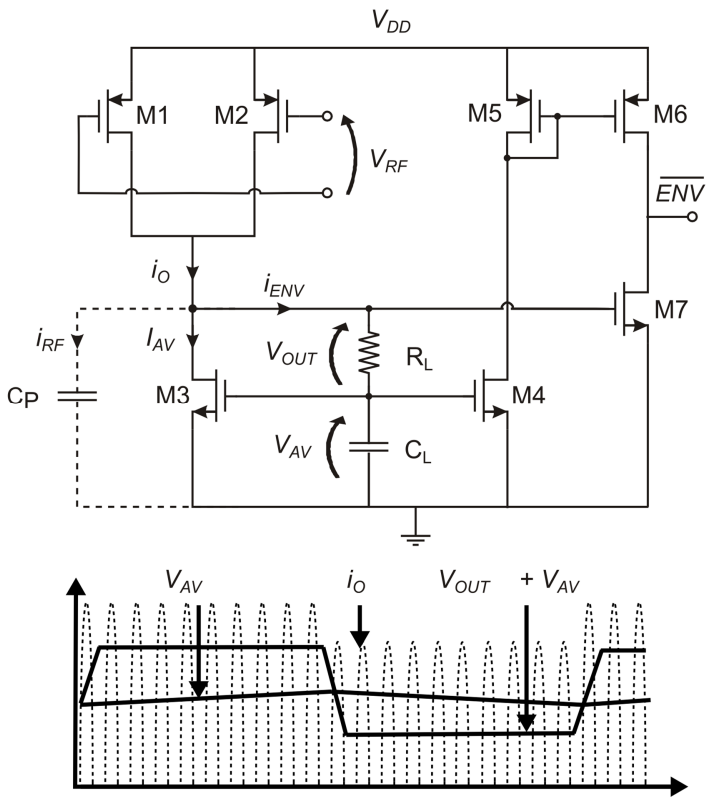

Fig. 11. ED schematic and qualitative sketch of the main waveforms.

diode connection of M3 through resistance $R_{\mathrm{L}}$. Provided that $C_{\mathrm{L}} \cdot R_{\mathrm{L}} \gg C_{\mathrm{L}} / g_{\mathrm{m} 3} \gg T_{\mathrm{BIT}}$, low-pass filter $R_{\mathrm{L}} C_{\mathrm{L}}$ makes the gate of $\mathrm{M} 3$ a virtual ground and envelope signal $i_{\mathrm{ENV}}$ flows into $R_{\mathrm{L}}$ thus producing the output voltage, $V_{\mathrm{OUT}}$, i.e. $R_{\mathrm{L}} \cdot i_{\mathrm{ENV}}$.

The "conversion gain" of the detector is related to $R_{\mathrm{L}}$ and the non-linear transconductance gain of the input pair. The self-biased load is a robust solution to deal with wide threshold tolerances and large RF input ranges. In our implementation, a resistance $R_{\mathrm{L}}$ of $40 \mathrm{M} \Omega$ was integrated. A discrete capacitor of $6 \mathrm{nF}$ was mounted for $C_{\mathrm{L}}$ on the same foil of the antenna for testing purposes. In comparison with more traditional diode-based ED schemes, the proposed topology shows several advantages.

- It guarantees a high output voltage thanks to the higher conversion gain with respect to traditional solutions (diode-connected rectifiers [8]-[9] or common drain topologies [24]). This avoids further amplification before the comparator, which would entail high ac-coupling capacitors to arrest offset and further current consumption.

- It has high input impedance, thus minimizing the power drawn by the reader.

- It is suitable for ASK signals with low $h$ thanks to the envelope-signal gain.

It is also worth noting that the differential-like topology of the input transistors allows compensation of the detrimental effect of the gate-drain capacitances. Indeed, a single-ended ED is 

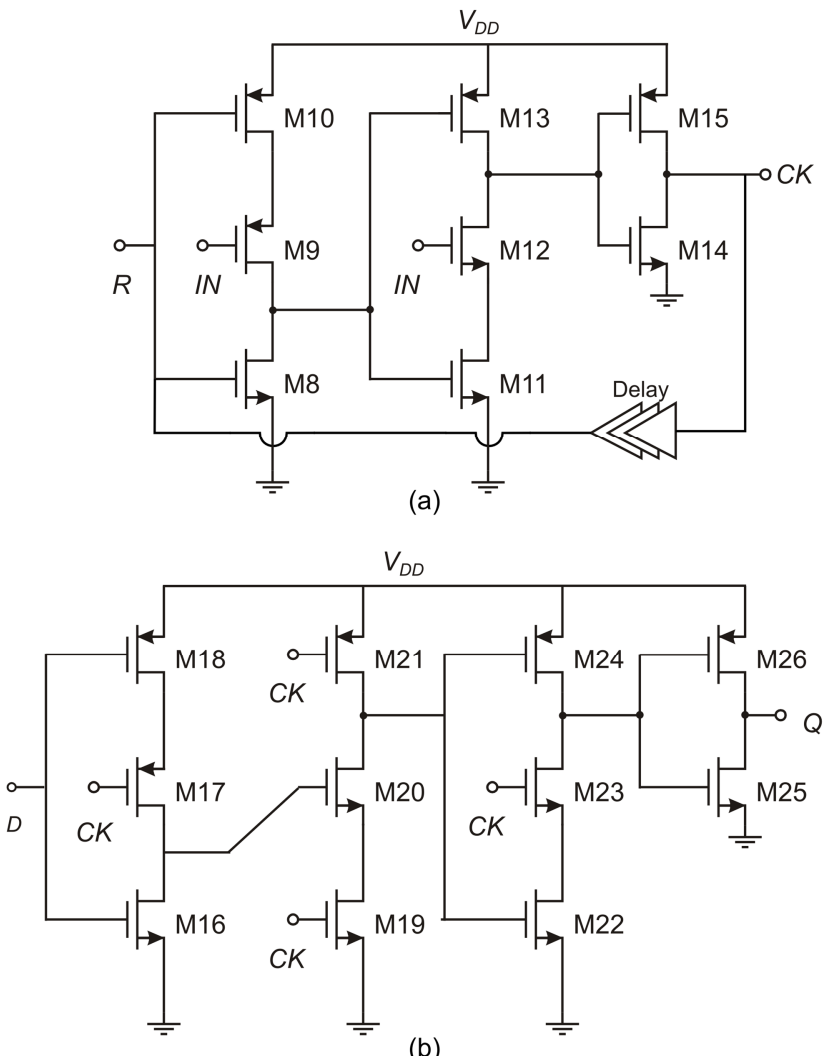

(b)

Fig. 12. Schematics of the clock decoder (a) and D-FF (b) [15]

not a good solution in this technology, due to the large overlap capacitance. Finally, a simple pseudo-differential comparator, M4-M7, provides at the ED output a quasi-rail-to-rail signal, $\overline{\mathrm{ENV}}$, which is large enough to drive the digital circuits.

The decoder digital circuits that recover data and clock (see Fig. 2) are implemented with dynamic logic cells to reduce transistor count and current consumption. The schematics of the clock decoder and the D-FF used for data recovery are shown in Figs. 12(a) and 12(b), respectively. The clock decoder exploits a customized topology, which minimizes the transistor count with respect to the traditional D-FF with reset. This simplification is made possible since both inputs $\mathrm{R}$ and IN are low before the beginning of a new bit, according to the coding scheme. The delay is implemented by a cascade of four inverters loaded by a capacitance $\left(C_{\text {DELAY }}\right)$.

\section{E. Code Recognition Unit}

The code recognition unit shown in Fig. 2 includes the two modules, RM and IVM, responsible for the tag synchronization and identity recognition, respectively. Both modules were designed using a transmission gate (TG) based approach. Indeed, TG-based logic guarantees presently lower area compared to fully-static implementations (around four times smaller in our technology) and higher robustness compared to dynamic logic and therefore is a good solution for complex digital circuitry. A detailed schematic of the code recognition unit is shown in Fig. 13. In RM, a 2-bit counter adds up the number of zeros in the input code (any "one" in the input resets the counter). After receiving four consecutive

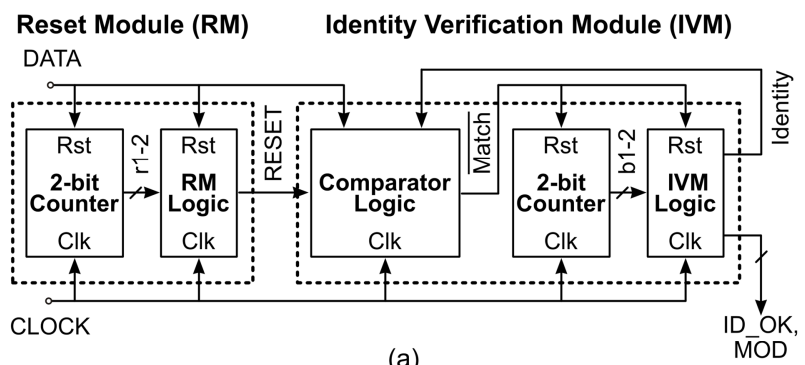

(a)
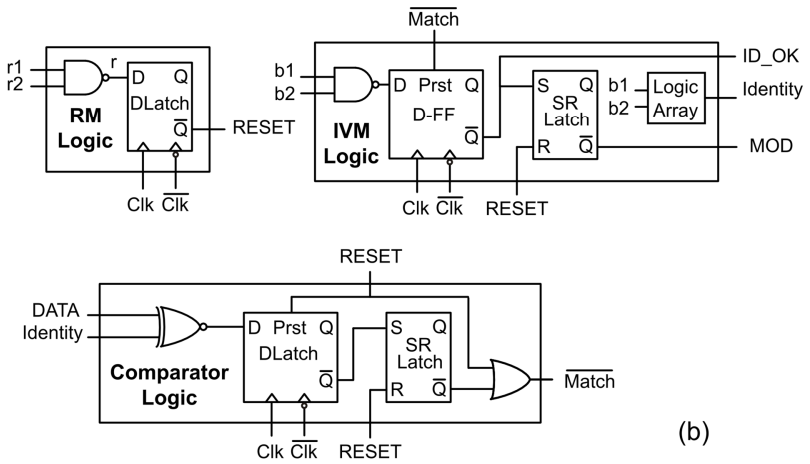

(b)

Fig. 13. Code recognition unit. (a) Block diagram. (b) Simplified schematics.

zeros (i.e., $r_{1} r_{2}=11$ and $r=0$ ), RM sends the reset signal, RESET, to IVM. This will announce the arrival of a new identity code to IVM by clearing all its FFs and latches. If there is a discrepancy between clock and data (e.g., the data is delayed with respect to the clock), signal " $r$ " may go temporarily high, before the counter is reset by the arrival of next " 1 " in the data flow. Since RESET is used to activate/lock some SR-latches asynchronously, it is important to prevent such temporary wrong activations. The D-latch in RM Logic block eliminates the possibility of sending such a false reset. The identity comparison is performed in the Comparator Logic block through an XOR gate. At each clock, the 2-bit counter and a logic array generate at the output of the Comparator Logic the correct tag identity code corresponding to the bit being received (the logic array is included in the IVM Logic block). In case of un-match the comparator output, $\overline{M a t c h}$, goes high and resets the counter. In this case $\overline{\text { Match }}$ remains active till the next RESET is received, resetting

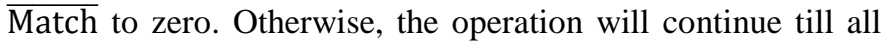
bits of the identification code are received and successfully compared. When this happens, the counter "Carry" bit generated in IVM Logic will go high and set ID_OK active, thus triggering the reply back by the tag. The output signal, MOD, which activates a ring oscillator, remains high until the next RESET is received. It is worth noting that the tag answers with a message (using the modulator) only after the correct code is received, according to the silent tag identification scheme.

\section{EXPERIMENTAL RESULTS}

The tag was fabricated on a PEN foil, as shown in Fig. 14. The photo highlights the macro-blocks constituting the circuit that are the rectifier, the receiver, and the code recognition unit. The overall active area of the circuit is $54 \mathrm{~cm}^{2}$. The area 


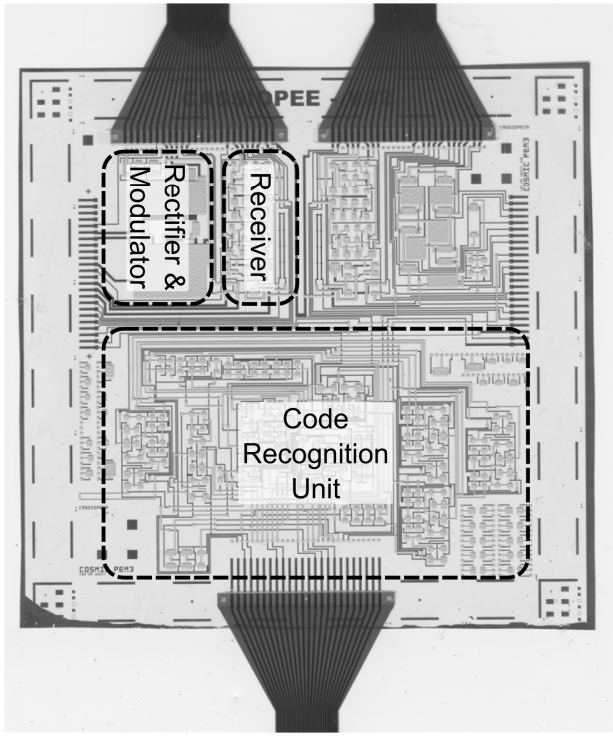

Fig. 14. Photo of the RFID tag foil bonded to flexible flat cables.

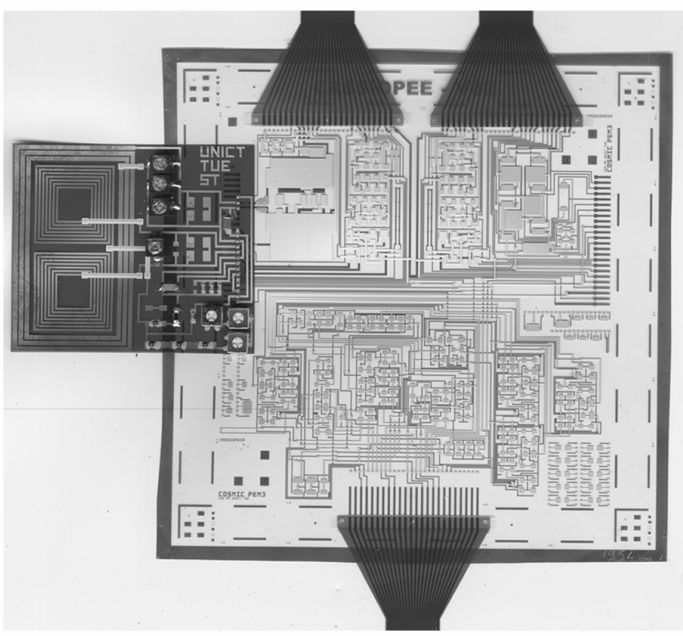

(a)

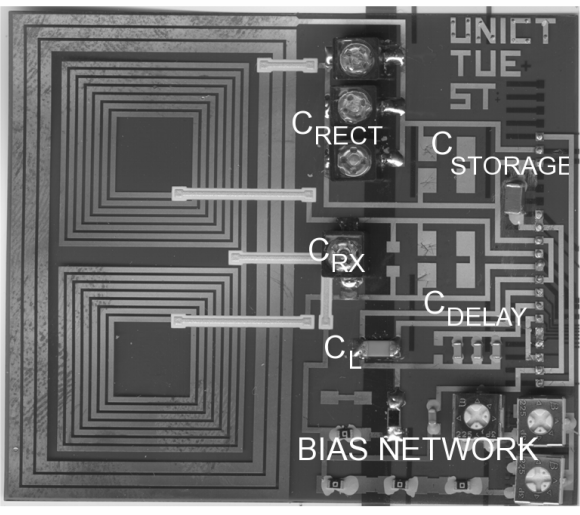

(b)

Fig. 15. (a) Photo of the complete RFID tag. (b) Detail of the $13-\mathrm{MHz}$ antenna foil with SMD components soldered on it.

in the right top quarter of the foil was used for other circuitry. Two flexible flat cables were bonded on the top and bottom of the foil using isotropic conductive glue. The flat cables were adopted to interface the tag with the lab instruments by means of a test board and make possible a complete characterization

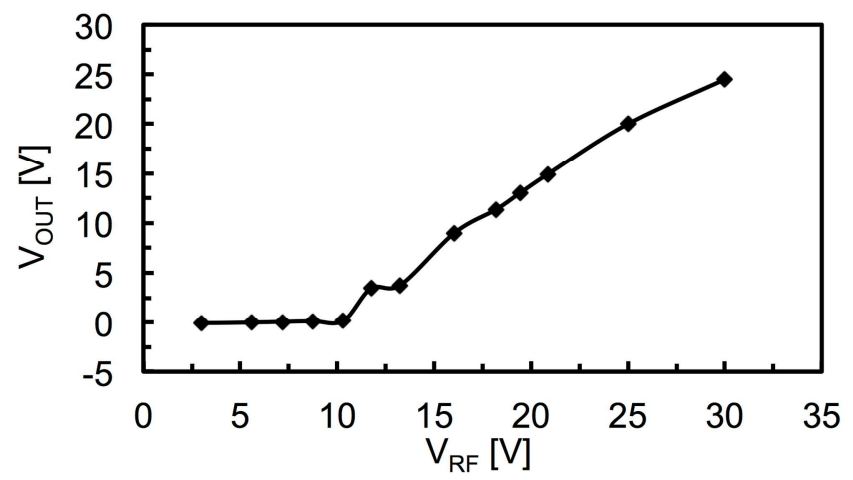

Fig. 16. Measured output voltage of the rectifier versus the RF input.
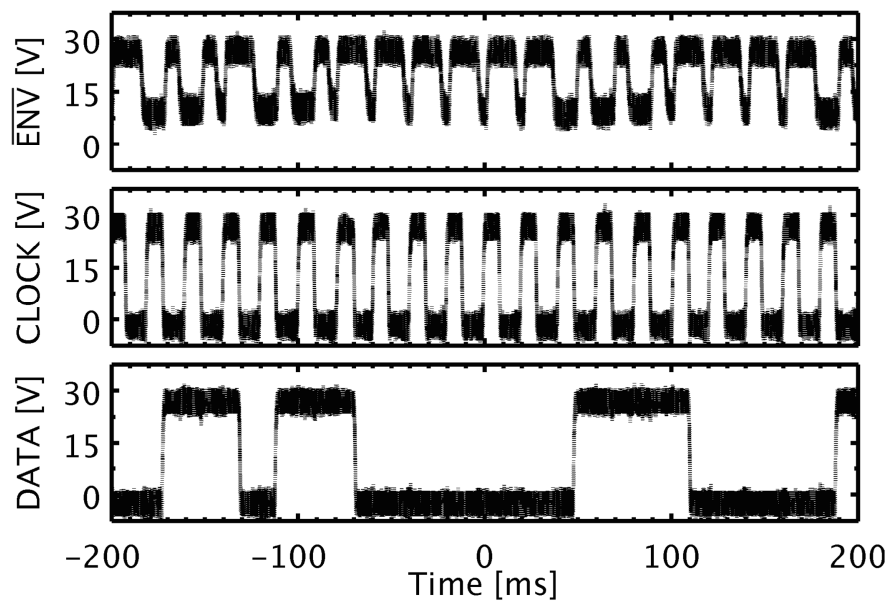

Fig. 17. Measured output signals of the receiver $\left(V_{\mathrm{DD}}=30 \mathrm{~V}, h=30 \%\right)$.

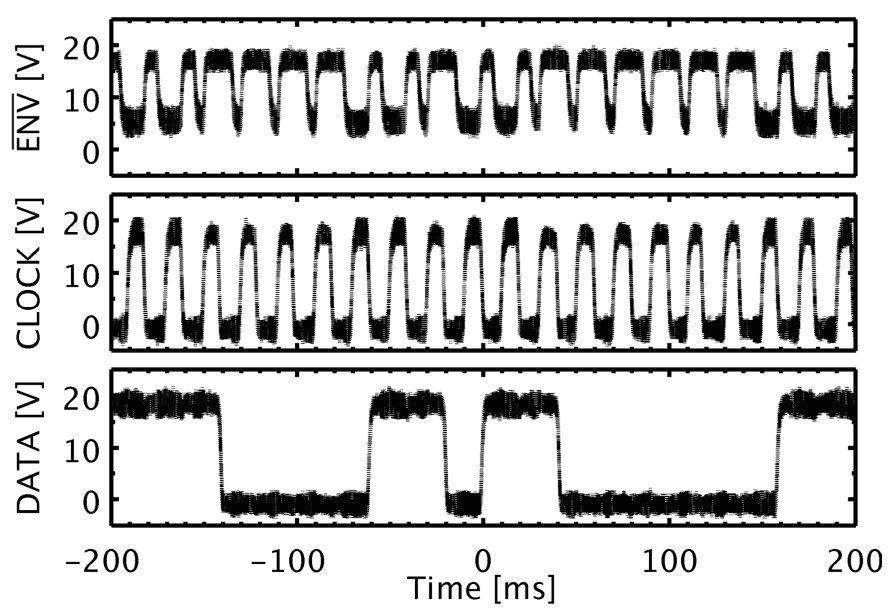

Fig. 18. Measured output signals of the receiver $\left(V_{\mathrm{DD}}=20 \mathrm{~V}, h=30 \%\right)$.

of both the overall circuit and the single macro-blocks before antenna assembling. To allow this test flexibility, the circuit macro-blocks were not directly connected on the PEN foil, but connections were performed by taking advantage of the antenna foil. To complete the tag, the PEN foil was then bonded to the polyimide foil with the antenna, as shown in Fig. 15. The polyimide foil was also used to house the two capacitors for the antenna matching networks (i.e., $C_{\mathrm{RECT}}$ and $C_{\mathrm{RX}}$ ), few passive components of the receiver (i.e., bias resistances, $C_{\mathrm{L}}$, and $C_{\text {DELAY }}$ ), and the storage capacitor of the rectifier, $C_{\mathrm{STORAgE}}$. The discrete capacitors, $C_{\mathrm{RECT}}, C_{\mathrm{RX}}, C_{\mathrm{L}}$, and $C_{\mathrm{DELAY}}$, can be directly printed on the RFID foil thanks to 

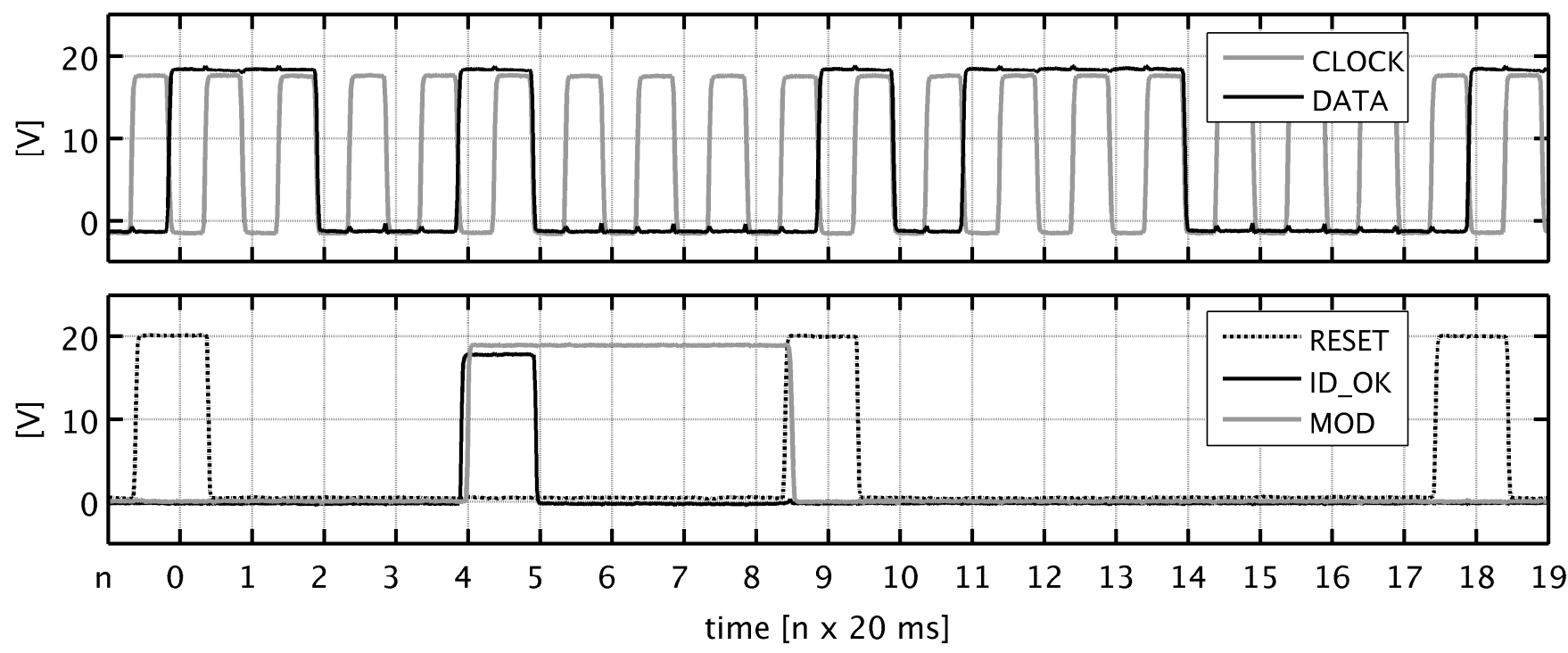

Fig. 19. Measurements of the code recognition unit for a $60-\mathrm{V}_{\mathrm{PP}}, 30 \%$ modulated $\mathrm{RF}$ input at $20-\mathrm{V}$ supply voltage.

the high-density (i.e., $2.15 \mathrm{nF} / \mathrm{cm}^{2}$ ) MIM capacitor provided by the adopted C-OTFT technology. As mentioned before, the antenna foil was also used to connect together the tag macro-blocks thus allowing their standalone characterization in the PEN foil. The available $8-\mu \mathrm{m}$ thick $\mathrm{Cu}$ metal was exploited for connections. In the following, experimental results of each macro-block and the complete tag are discussed. Measurements were carried out on a total of 7 RFID samples.

The rectifier was characterized under different amplitudes of the sinusoidal RF input with an equivalent full-tag load of $0.7 \mathrm{M} \Omega$. It generates an output voltage $\left(V_{\mathrm{DD}}\right)$ of $25 \mathrm{~V}$ for a 13.56-MHz input signal, $V_{\mathrm{RF}}$, of $60 \mathrm{~V}_{\mathrm{PP}}$. Output voltage measurements as a function of the RF peak voltage are summarized in Fig. 16. Figs. 17 and 18 show the main measured signals of the receiver for a $60-\mathrm{V}_{\mathrm{PP}} \mathrm{RF}$ input with $h$ of $30 \%$ at $30-\mathrm{V}$ and $20-\mathrm{V}$ power supply, respectively. It is worth noting that due to the lower supply voltages and hence the reduced current capability at sub-threshold operation, ED requires an RF input signal larger than the supply voltage. Fig. 19 shows the measurement of the code recognition unit at $20-\mathrm{V}$ supply voltage for a $60-\mathrm{V}_{\mathrm{PP}}, 30 \%$ modulated ASK RF input. Two different identity codes were adopted in this work, with one time programmability enabled by laser trimming. In the reported test, the reset signal code is "10000", the tag identity code is " 0011 ", and the un-match code is " 1011 ". As expected, the measured signal ID_OK goes high only after the sequence "1100" is received (i.e., $n=4$ in Fig. 19), thus triggering the reply back. Signal MOD is high only after the correct identity code is received. It goes low after subsequent signal RESET goes high (i.e., $n=9$ in Fig. 19). The functionality of the code recognition unit was successfully verified for several supply voltages, from $40 \mathrm{~V}$ to $20 \mathrm{~V}$.

The complete RFID tag together with the flexible antenna was tested thanks to two interface boards, as shown in the measurement setup in Fig. 20. The RFID was successfully

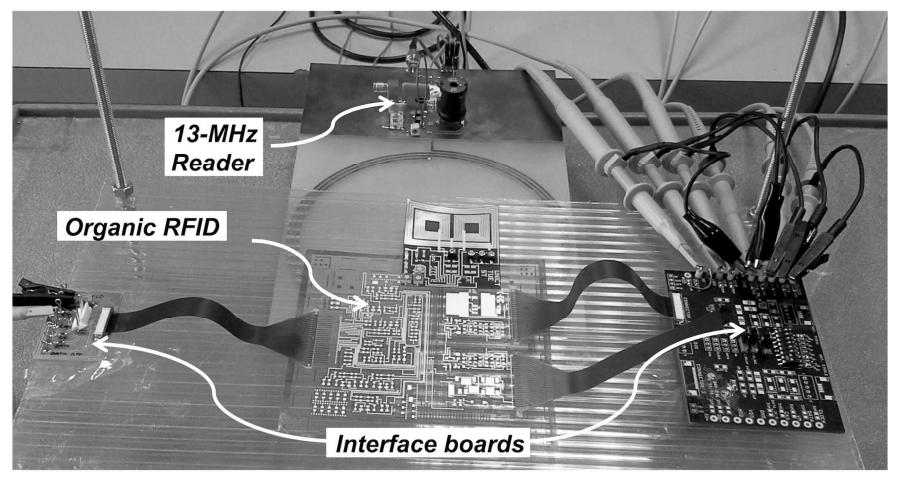

Fig. 20. Measurement setup for the printed C-OTFT RFID tag.
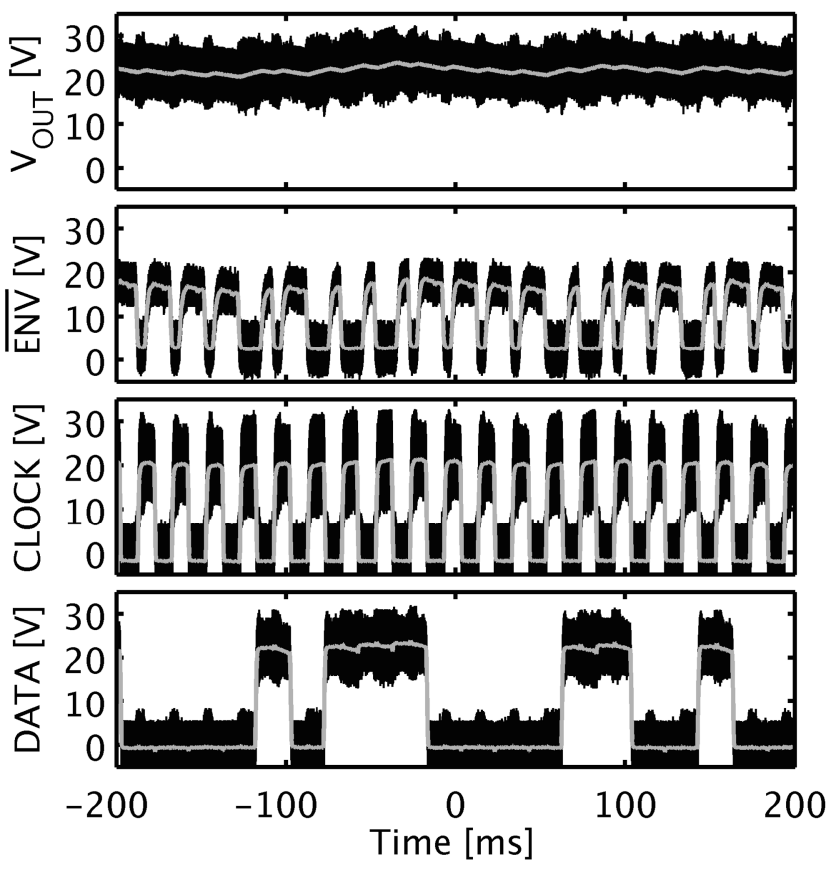

Fig. 21. Tag measurement waveforms for a $60-\mathrm{V}_{\mathrm{PP}}, 20 \%$ modulated 13.56-MHz input signal. 
tested with a $60-\mathrm{V}_{\mathrm{PP}} \mathrm{RF}$ input voltage. For $h$ of $50 \%, 30 \%$, and $20 \%$, the measured rectifier output, $V_{\text {OUT, was }} 20 \mathrm{~V}, 22 \mathrm{~V}$, and $24 \mathrm{~V}$ respectively. Little variation was observed for a reading range from $2 \mathrm{~cm}$ to $5 \mathrm{~cm}$. The rectifier output and receiver main signals for a $60-\mathrm{V}_{\mathrm{PP}} \mathrm{RF}$ input are shown in Fig. 21 with and without averaging. The $20 \%$ ASK modulation of the input signal can be recognized by looking at the RF noise in signal DATA. As far as the modulator is concerned, the glue attachment affected the functionality of some TFTs since the modulator was placed too close to top flat cable contacts. This drawback prevented from characterizing the transmission link.

Main performance of the proposed organic RFID tag is summarized in Table III.

TABLE III. SUMMARIZED RFID PERFORMANCE

\begin{tabular}{lc}
\hline \hline Parameter & Values \\
\hline RF frequency $\left(f_{\mathrm{RF}}\right)$ & $13.56 \mathrm{MHz}$ \\
Modulation depth $(h)$ & $50-20 \%$ \\
Supply voltage & $20-24 \mathrm{~V}$ \\
Reading range & $2-5 \mathrm{~cm}$ \\
Code bits & 4 \\
Max. bit rate & $50 \mathrm{bit} / \mathrm{s}$ \\
Antenna area & $15 \mathrm{~cm}^{2}$ \\
Circuit area & $54 \mathrm{~cm}^{2}$ \\
\hline
\end{tabular}

\section{CONCLUSION}

The implementation of an integrated 13.56-MHz RFID tag in a printed C-OTFT technology on flexible substrate has been successfully demonstrated for the first time. The circuit is the most complex mixed-signal integrated system ever published in printed C-OTFT technology, with more than 250 organic TFTs on the same foil. Its functionality was verified at a supply voltage as low as $24 \mathrm{~V}$, thus demonstrating the potential of sub-threshold operation for C-OTFTs.

This work advances the state of the art since it demonstrates the implementation of a very complex system on a printed organic technology using several techniques at different levels: system (i.e., secure identification scheme and ASK modulation), technology (i.e., flexible antennas and C-OTFT technology), tag architecture (i.e., three-coil antenna), and circuit (i.e., active envelope detector and sub-threshold operation).

\section{ACKNOWLEDGMENTS}

The authors would like to thank E. Cintolo and A. Castorina of STMicroelectronics, Catania, Italy for the layout and measurement support, respectively.

\section{REFERENCES}

[1] G. Scarpa, A.-L. Idzko, A. Yadav, E. Martin, and S. Thalhammer "Toward cheap disposable sensing devices for biological assays," IEEE Trans. Nanotechnol. vol. 9, no. 5, pp. 527-532, Sep. 2010.

[2] J. Chang, Ge. Tong, E. Sanchez-Sinencio, "Challenges of printed electronics on flexible substrates," in Proc. IEEE International Midwest
Symposium on Circuits and Systems (MWSCAS), Aug. 2012, pp. 582-585.

[3] H. Marien, M. S. J. Steyaert, E. van Veenendaal, and P. Heremans, "Analog building blocks for organic smart sensor systems in organic thin-film transistor technology on flexible plastic foil," IEEE J. Solid-State Circuits, vol. 47, pp. 1712-1720, July 2012.

[4] G. Maiellaro, E. Ragonese, R. Gwoziecki, S. Jacobs, N. Marjanović, M. Chrapa, J. Schleuniger, and G. Palmisano, "Ambient light organic sensor in a printed complementary organic TFT technology on flexible plastic foil," IEEE Trans. Circuits Syst. I, vol. 61, pp. 1036-1043, April 2014.

[5] E. Cantatore, T. C. T. Geuns, G. H. Gelinck, E. van Veenendaal, A. F. A. Gruijthuijsen, L. Schrijnemakers, S. Drews, D. M. de Leeuw, "A 13.56 MHz RFID system based on organic transponders," IEEE J. Solid-State Circuits, vol. 42, p. 84 - 92, Jan. 2007.

[6] K. Myny, et al., "An inductively-coupled 64b organic RFID tag operating at $13.56 \mathrm{MHz}$ with a data rate of $787 \mathrm{~b} / \mathrm{s} "$, in Proc. IEEE Int. Solid-State Circuits Conf. Tech. Dig., Feb. 2008, pp. 290-292.

[7] R. Blache, J. Krumm, and W. Fix, "Organic CMOS circuits for RFID applications," in Proc. IEEE Int. Solid-State Circuits Conf. Tech. Dig., Feb. 2009, pp. 208-210.

[8] K. Myny et al., "Bidirectional communication in an HF hybrid organic/solution-processed metal-oxide RFID tag," in Proc. IEEE Int. Solid-State Circuits Conf. Tech. Dig., Feb. 2012, pp. 312-314.

[9] K. Myny et al., "Bidirectional communication in an HF Hybrid organic/solution-processed metal-oxide RFID tag," IEEE Trans. on Electron Devices, vol. 61, pp.2387-2393, July 2014.

[10] A Daami et al., "Fully printed organic CMOS technology on plastic substrates for digital and analog applications," in Proc. IEEE Int. Solid-State Circuits Conf. Tech. Dig., Feb. 2011, pp. 328-329.

[11] S. Jacob et al., "High performance printed $\mathrm{N}$ and P-type OTFTs enabling digital and analog complementary circuits on flexible plastic substrate," Elsevier Solid-State Electronics, pp. 167-178, June 2013.

[12] S Abdinia et al., "Design of analog and digital building blocks in a fully printed complementary organic technology," in Proc. IEEE Eur. Solid-State Circuits Conf., Sep. 2012, pp. 145-148.

[13] G. Maiellaro, E. Ragonese, A. Castorina, S. Jacob, M. Benwadih, R. Coppard, E. Cantatore, and G. Palmisano, "High-gain operational transconductance amplifiers in a printed complementary organic TFT technology on flexible foil," IEEE Trans. Circuits Syst. I, vol. 60, pp. 3117-3125, Dec. 2013.

[14] S. Abdinia et al., "A 4b ADC manufactured in a fully-printed organic complementary technology including resistors," in Proc. IEEE Int. Solid-State Circuits Conf. Tech. Dig., Feb. 2013 pp. 106-107.

[15] V. Fiore E. Ragonese, S. Abdinia, S. Jacob, I. Chartier, R. Coppard, A. van Roermund, E. Cantatore, and G. Palmisano, "A 13.56MHz RFID tag with active envelope detection in an organic complementary TFT technology," in Proc. IEEE Int. Solid-State Circuits Conf. Tech. Dig., Feb. 2014, pp. 492-493.

[16] H. Moran, et al., "Selective addressing transponders" US patent app. 13/0154799A1, filed 9 June 2011.

[17] M. Benwadih, et al., "Integration of a graphene ink as gate electrode for printed organic complementary thin-film transistors", Organic Electronics, pp. 614-621, Feb. 2014.

[18] S. S. Mohan, M. del Mar Hershenson, S. P. Boyd, T. H. Lee, "Simple accurate expressions for planar spiral inductances," IEEE J. Solid-State Circuits, vol. 34, pp.1419-1424, Oct. 1999.

[19] A. Scuderi, E. Ragonese, T. Biondi, and G. Palmisano, "Integrated Inductors and Transformers: Characterization, Design and Modeling for RF and mm-Wave Applications. Boca Raton, FL: CRC, 2010.

[20] A. Abdinia, F. Torricelli, G. Maiellaro, R. Coppard, A. Daami, S. Jacob, L. Mariucci, G. Palmisano, E. Ragonese, F. Tramontana, A.H.M. van Roermund, E. Cantatore, "Variation-based design of an AM demodulator in a printed complementary organic technology," Elsevier Organic Electronics, vol. 15, pp. 904-912, April 2014.

[21] J. F. Dickson, "On-chip high-voltage generation in NMOS integrated circuits using an improved voltage multiplier technique," IEEE $J$. Solid-State Circuits, vol. 11, pp. 374-378, 1976.

[22] J. F. Dickson, "Voltage multiplier employing clock gated transistor chain," U.S. patent 4,214,174, 1980.

[23] G. Papotto, F. Carrara and G. Palmisano., "A 90-nm CMOS threshold-compensated RF energy harvester," IEEE J. Solid-State Circuits, vol. 46, pp. 1985-1997, 2011.

[24] R. G. Meyer, "Low-power monolithic RF peak detector analysis," IEEE J. Solid-State Circuits, vol. 30, pp. 65-67, Jan 1995. 


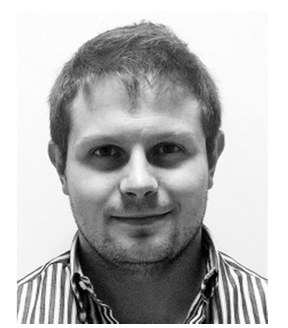

Vincenzo Fiore (M'13) received the Master degree in microelectronics, from the University of Catania, Italy, in 2012. He is currently pursuing the Ph.D. in Systems Engineering at the same university. Since 2011, he has been with the Radio Frequency Advanced Design Center (RF-ADC), a joined research center supported by University of Catania and STMicroelectronics, where he is involved in the design of mixed signal and RF ICs, mainly focused on galvanic-isolated integrated systems. In last years, he worked in the field of organic electronics within the framework of the COSMIC European Research Projects.

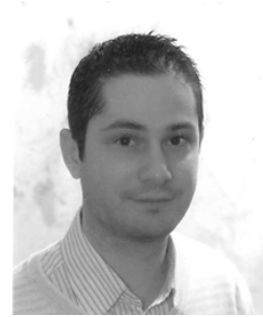

Projects.
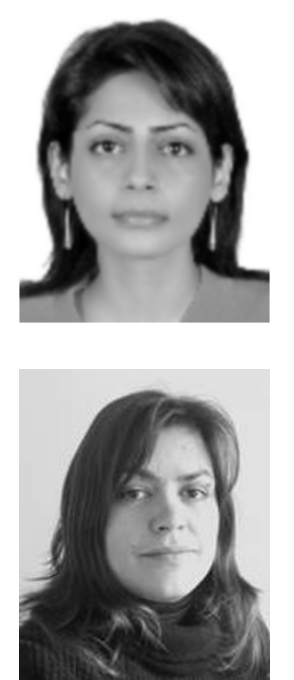

Stephanie Jacob received the M.S. degree in Microelectronics and Telecommunications from the Ecole Polytechnique Universitaire de Marseille, France, in 2004 and the Ph.D. degree in microelectronics from the University of Provence, France, in 2008. Her Ph.D. work was carried out in CEA-LETI and ATMEL Rousset, France, on the integration, characterization and modelling of silicon nanocrystal memories. Since 2008, she has joined CEA-LITEN, France to work on the electrical characterization and modelling of organic transistors on flexible substrate. She is the co-author of more than 20 papers in international journals and conference proceedings.

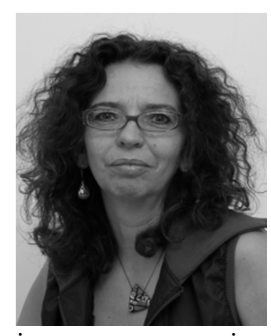

Isabelle Chartier is graduated as an engineer in general optics from the Institut d'Optique - Paris, France in 1986 and joined CEA-Grenoble in 1989.

She is currently Business manager for Printed Electronic at CEA-LITEN. Since 2012 she is director of PICTIC, the French Printing Platform for Organic Electronics development, prototyping and industrialization focused on Large Area Sensing Surface integrating printed OTFT, sensors and actuators. PICTIC is addressing applications such as image sensor, user interfaces, conformable sensing surfaces etc.

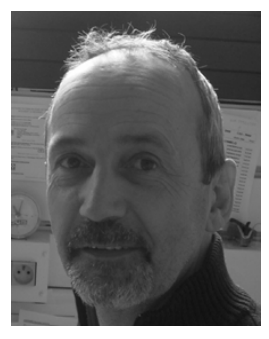

Romain Coppard obtained the Ph.D. degree in semiconductor device physics in 1984 . He has been working in the field of organic electronics since 2007, and held before various positions at major silicon microelectronics companies (Alcatel, Applied Materials, ATMEL). He is currently heading the Laboratory of Printed Electronics Devices in CEA Liten (Grenoble, France), in charge of developing the sheet-to-sheet printed organic CMOS technology for the COSMIC project. He held 5 patents and co-authored more than 50 papers.

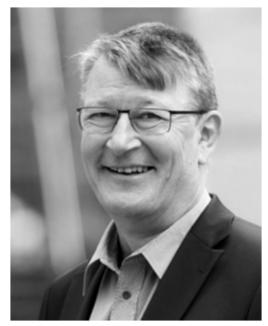

Gerhard Klink studied physics with focus on surface science at the Technical University Munich. After finishing his studies with the diploma degree in 1987 he joined the Fraunhofer Society, where he started to work on microsystems technology. During different research projects he acquired a profound knowledge on thick and thin film technology in the fields of hybrid circuits, electronic packaging, sensors and actuators. Since 1998 he is working on process development for flexible electronic systems and corresponding roll-to-roll manufacturing methods. At present he is managing the Polytronic technology group and has lead several projects in Organic and Large Area Electronics.

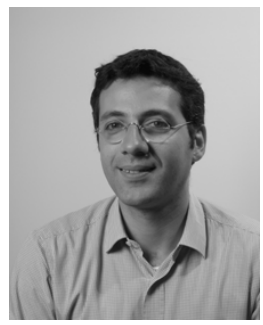

Eugenio Cantatore (M'98-SM'14) received his Master and Ph.D. Degree in Electrical Engineering from Politecnico di Bari, Bari, Italy in 1993 and 1997 respectively. From 1994 to 1999 he was first a $\mathrm{Ph} . \mathrm{D}$. student and then a fellow at the European Laboratory for Particle Physics (CERN) Geneva, Switzerland. In 1999 he moved to Philips Research, Eindhoven, The Netherlands as senior scientist and in 2007 joined the Eindhoven University of Technology where he is associate professor. His research interests include the design and characterization of electronic circuits exploiting emerging technologies as well as the design of ultra-low power micro-systems for medical applications. Dr. Cantatore authored or co-authored more than 120 papers in journals and conference proceedings, and 13 patents or patent applications. He is active in the Technical Program Committees of ESSDERC, ESSCIRC and ISSCC and has been member of the Executive Committee of ISSCC. Since 2013 he is chair of the Technology Directions subcommittee of ISSCC. In 2006 he received from ISSCC the Beatrice Winner Award for Editorial Excellence and was nominated in the Scientific American top 50 list. He received the Philips Research Invention Award in 2007 and in 2012 the Best Paper Award from ESSDERC.

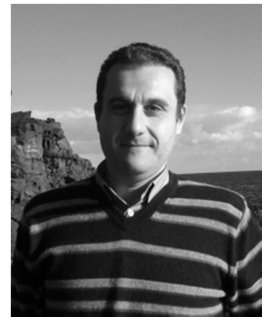

Egidio Ragonese (M'03-SM'12) received the Laurea degree in electronic engineering and the Ph.D. degree in electronics engineering from the University of Catania, Italy, in 1999 and 2003, respectively. Since 1999 he has been with the Radio Frequency Advanced Design Center (RF-ADC), a joint research center supported by the University of Catania and STMicroelectronics. In 2003 and 2008, he joined the DIEEI at the University of Catania as Research Associate and Assistant Professor, respectively. Since October 2011, he has been with STMicroelectronics, Catania, Italy. His research interests included RF transceivers for wireless communications and $\mathrm{mm}$-wave circuits for radar applications. Dr. Ragonese is co-author of 60 papers, several patents and two books. Recently, he has been also active in the field of organic electronics within two European Research Projects.

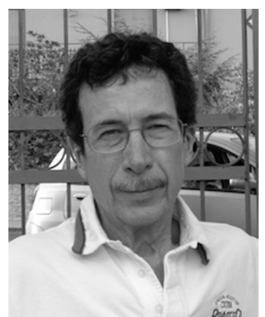

Giuseppe Palmisano (M'08-SM'09) received the Laurea degree in electronic engineering from the University of Pavia, Pavia, Italy, in 1982.

From 1983 to 1991, he was Researcher with the Department of Electronics, University of Pavia, where he was involved in CMOS and BiCMOS analog integrated circuit design. In 1992, he was a Visiting Professor with Universidad Autonoma Metropolitana (UAM), Mexico City, Mexico, where he taught microelectronics for Ph.D. students. In 1993 and 2000, he joined the Faculty of Engineering at the University of Catania, Catania, Italy, as Associate Professor and Full Professor, respectively, teaching microelectronics. Since 1999, he has been leading the Radio Frequency Advanced Design Center (RF-ADC), a joint research center supported by University of Catania and STMicroelectronics, Catania, Italy. He has supervised the design of several innovative analog integrated circuits and systems within the framework of national and European research projects and in collaboration with electronic industries. He is the coauthor of more than 250 papers in international journals and conference proceedings, around 50 international patents, and 3 books. His research interests lie in the area of analog integrated circuit design with special emphasis to RF applications. Recently, he has been facing remotely-powered transceivers with RF energy harvesting and printed electronics with organic thin film technologies. 